\title{
High incidence of hepatitis B infection after treatment for paediatric cancer at a teaching hospital in Baghdad
}

\author{
M. F. Al-Jadiry, ${ }^{1}$ M. Al-Khafagi, ${ }^{2}$ A.F. Al-Darraji, ${ }^{2}$ R.M. Al-Saeed, ${ }^{2}$ S.F.Al-Badri ${ }^{2}$ and S.A. Al-Hadad ${ }^{7}$
}

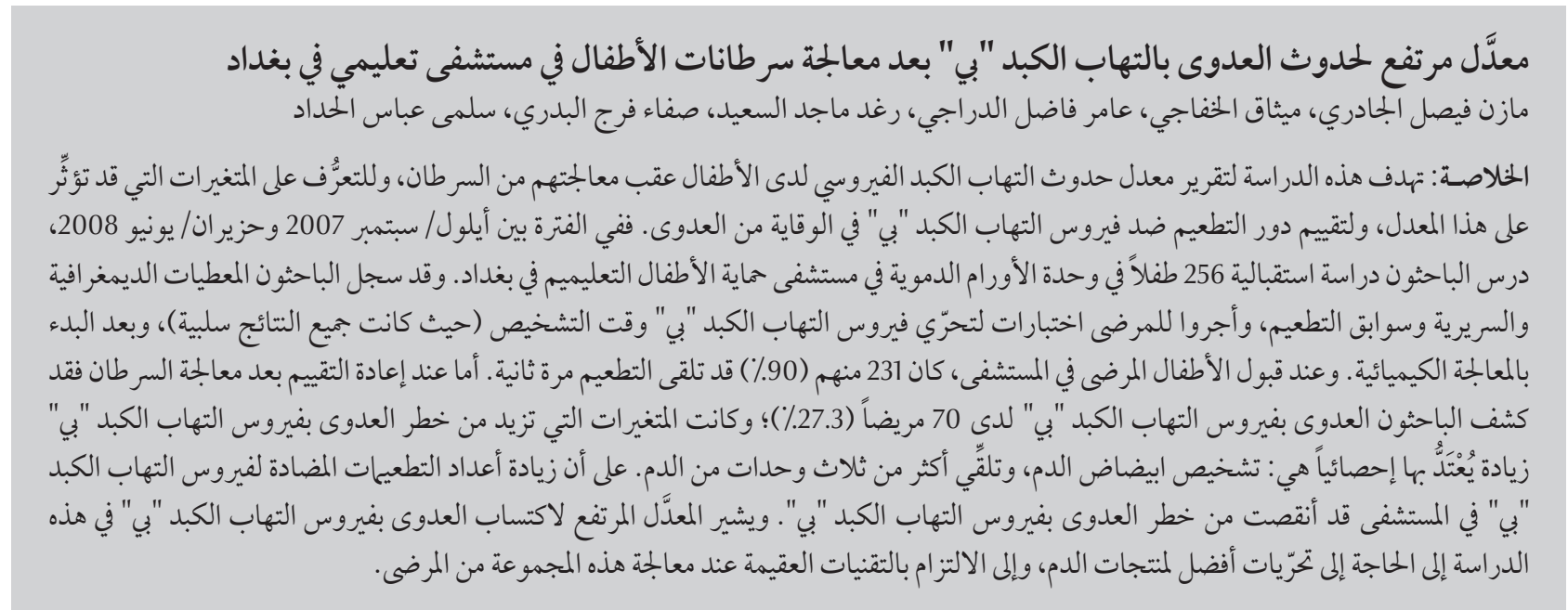

ABSTRACT This study estimated the incidence of viral hepatitis in children treated for cancer, to identify variables that could affect this incidence and to assess the role of hepatitis B virus (HBV) vaccination in preventing infection. Between September 2007 and June 2008, 256 children in the haemato-oncology unit at the Children's Welfare Teaching Hospital, Baghdad, were studied prospectively. Demographic and clinical data and vaccination history were recorded. Patients were tested for HBV at the time of diagnosis (all were negative) and after starting chemotherapy. On admission to the unit, 231 patients (90.2\%) were revaccinated. At reassessment after treatment for cancer, HBV infection was found in 70 patients (27.3\%). The variables that significantly increased the risk for HBV infection were a diagnosis of leukaemia and receiving more than 3 units of blood. A higher number of HBV vaccinations in hospital reduced the risk for HBV infection. The high rate of acquisition of HBV infection found in this study indicates the need for better screening of blood products and adherence to aseptic techniques in management of this group of patients.

Incidence élevée de l'infection par le virus de l'hépatite B après un traitement pour un cancer chez l'enfant à l'hôpital universitaire de Bagdad

RÉSUMÉ La présente étude a estimé l'incidence de l'hépatite virale chez les enfants traités pour un cancer, afin d'identifier les variables qui pourraient influer sur son incidence et d'évaluer le rôle de la vaccination contre le virus de l'hépatite B dans la prévention de l'infection. Entre septembre 2007 et juin 2008, 256 enfants admis au service d'hémato-oncologie de l'hôpital pédiatrique universitaire à vocation sociale de Bagdad ont fait l'objet d'une étude prospective. Les données démographiques et cliniques ainsi que les antécédents de vaccination ont été notés. Les patients ont passé un test de dépistage de l'infection par le virus de l'hépatite B à la pose du diagnostic (tous étaient négatifs) et après l'instauration de la chimiothérapie. Lors de leur admission dans le service, 231 patients (90,2\%) ont été revaccinés. Après le traitement pour le cancer, un nouveau dépistage a été conduit et une infection par le virus de l'hépatite B a été retrouvée chez 70 patients $(27,3 \%)$. Un diagnostic de leucémie et une transfusion de plus de trois unités de sang étaient les variables augmentant nettement le risque d'infection par le virus de l'hépatite B. Un nombre plus élevé de vaccinations contre le virus de l'hépatite B à l'hôpital réduisait le risque d'une telle infection. Le taux élevé de nouvelles infections par le virus de l'hépatite B observé dans cette étude met en évidence la nécessité d'un meilleur dépistage des produits sanguins et d'une meilleure observance des techniques d'asepsie dans la prise en charge de ce groupe de patients. 


\section{Introduction}

Children living in intermediate- and high-endemicity areas for hepatitis B virus (HBV) are at risk of getting the infection, especially those children with cancer who are obliged to receive intensive cytostatic chemotherapy, which requires multiple blood transfusions and causes immunodeficiency. HBV vaccination of seronegative patients at diagnosis may be recommended $[1,2]$.

Iraq is a developing country, where $\mathrm{HBV}$ and hepatitis $\mathrm{C}$ virus (HCV) infections are still prevalent, with an HBV carrier rate of $2 \%-5 \%$. Although Iraq includes $\mathrm{HBV}$ vaccination in its Expanded Programme on Immunization, the coverage rate is less than $80 \%$ $[3,4]$.

Hospital-acquired HBV and HCV infections continue to occur despite increased awareness of the problem among the medical community [2]. Children with cancer need frequent blood counts, invasive diagnostic procedures (e.g. bone marrow aspiration and biopsy), intravenous therapy and surgery, which may contribute to their risk for acquiring $\mathrm{HBV}$ infection.

We determined the risk for infection with hepatitis viruses among children being treated for cancer at our hospital, the Children's Welfare Teaching Hospital, Baghdad. We also assessed the role of $\mathrm{HBV}$ vaccination in preventing infection.

\section{Methods}

Between September 2007 and June 2008 , all 256 children $\leq 15$ years old (the upper limit for receiving children in this hospital is 14 years) who were being treated for cancer or who had finished treatment and were attending for followup at the Children's Welfare Teaching Hospital, Baghdad, were studied.

Demographic and clinical information was obtained, including name of child, date of birth, sex, residence, type of cancer, date of diagnosis, result of hepatitis screening at the time of diagnosis, duration of observation, presumed number of hepatitis vaccinations given at home, number of $\mathrm{HBV}$ vaccinations given at the hospital, result of hepatitis screening at the time of reassessment, number of blood transfusions and hospital in which they were done. The sources for this information were the parents, the hospital records, and medical notes and documentation about the child's treatment held by the parents. Simple written consent was obtained from the families although all procedures and investigations were within the normal range of our work as we do frequent screening for hepatitis (every 3 months) because of high incidence in our patients.

The factors which were considered might have a statistically significant impact on the incidence of hepatitis B among the children were age, type of malignancy, residence, number of blood transfusions and hospital in which they were done, vaccination at home in the national immunization programme and vaccination at the hospital.

Blood samples were tested for hepatitis B surface antigen ( $\mathrm{HBsAg}$ ) and anti-hepatitis $\mathrm{C}$ antibody (anti-HCV) with commercially available enzymelinked immunosorbent assay (ELISA) diagnostic kits. Hepanostika HBsAg ultra 576T (bioMèrieux) was used to screen for HBV and Hepanostika HBsAg Ultra 25T for confirmation. Bioelisa HCV 480T (Biokit) was used to screening for HVC, but no confirmatory tests were available.

Multi-transfused patients were defined as those who had received more than 3 units of blood.

\section{Statistical analysis}

Statistical analysis was performed with GraphPad Instat 3 for Windows. Descriptive statistics were reported. The chisquared test for trend and the Fisher exact test were used to compare groups. Statistical significance was set at $P<$ 0.05 .

\section{Results}

The majority of the children (192/256, $75.0 \%)$ were diagnosed between 2006 and 2007; for the remainder, the diagnosis had been made between 2001 and 2006.

All patients had a negative screen for $\mathrm{HBV}$ and $\mathrm{HCV}$ at the time of diagnosis (the result for HCV was missing for 1 patient). At the time of reassessment, 70/256 (27.3\%) patients were positive (screening and confirmatory test) for HBV, and 19/244 (7.8\%) were positive for $\mathrm{HCV}$ in the screening test (12 patients were not screened for HCV because of lack of laboratory materials).

The median age of the children in the study was 5 years and 5 months (range, 3 months to 15 years and 5 months); 168 (65.6\%) were boys (male: female ratio, 1.9:1) (Table 1). The patients were referred from various parts of Iraq, however, the majority $(149,58.2 \%)$ were from Baghdad.

The duration of observation from the time of diagnosis of any cancer until the last screen for hepatitis was 2-82 months, with a median of 15.5 months. The majority of patients $(166,64.8 \%)$ had leukaemia and 59 (35.5\%) of these were found to be HBsAg positive, the earliest at 3 months and the last at 80 months during the 2-82 months observation period (Table 1).

The number of units of blood transfused ranged from 0 to 30 units, with a median of 7 units; 158 children (of the 231 who received transfusions) were transfused exclusively in our hospital (Table 1).

Most children had received 3 doses of HBV vaccine at home according to the national Iraqi vaccination schedule ( 3 doses: birth, 2 months and 6 months); 40 children had received 
fewer than 3 , and 14 children had not received any (Table 1). It is the policy of our unit that all children receive HBV vaccination on admission: 231 children received a variable number of doses, while 25 children received no vaccine owing to a shortage of supply (Table 1). The rate of infection with HBV was 28/152 (18.4\%) among children receiving 3 or 4 doses of HBV vaccine in hospital and 42/103 (40.7\%) receiving $<3$ doses.
Statistically significantly higher incidences of hepatitis B were found among children with leukaemia (35.5\%) $(P<0.0001)$ and among those who had received more than 3 units of blood $(34.0 \%)(P<0.0105)$; a greater number of doses of hepatitis $B$ vaccine reduced the incidence $(P<0.0001)$.

Duration of follow-up did not show any statistically significant correlation with incidence of hepatitis $(P$ $=0.1275$ ).

\section{Discussion}

A high incidence of $\mathrm{HBV}$ infection (27\%) was found in children with cancer treated in our unit, especially among those with leukaemia and those who received more than 3 units of blood; however, vaccination at the hospital had a significant impact on preventing HBV infection.

The prevalence of HBsAg at the time of diagnosis was zero, which is

\begin{tabular}{|c|c|c|c|c|c|}
\hline \multirow[t]{2}{*}{ Characteristic } & \multicolumn{2}{|c|}{ Total } & \multicolumn{2}{|c|}{ HBsAg +ve } & \multirow[t]{2}{*}{$P$-value } \\
\hline & No. & $\%$ & No. & $\%$ & \\
\hline Age (years) & & & & & $0.0680^{\mathrm{a}}$ \\
\hline $1-6$ & 177 & 69.1 & 42 & 23.7 & \\
\hline$>6$ & 79 & 30.9 & 28 & 35.4 & \\
\hline Sex & & & & & $1.000^{\mathrm{a}}$ \\
\hline Male & 168 & 65.6 & 46 & 27.3 & \\
\hline Female & 88 & 34.4 & 24 & 27.2 & \\
\hline \multicolumn{6}{|l|}{ Site of cancer } \\
\hline Leukaemia & 166 & 64.8 & 59 & 35.5 & \\
\hline Other & 90 & 35.1 & 11 & 12.2 & \\
\hline Residence & & & & & $0.5710^{\mathrm{a}}$ \\
\hline Baghdad & 149 & 58.2 & 43 & 28.8 & \\
\hline Other & 107 & 41.8 & 27 & 25.2 & \\
\hline Blood transfusion (no. of units) & & & & & 0.0105 \\
\hline 0 & 25 & 9.8 & 1 & 4.0 & \\
\hline $1-3$ & 131 & 51.2 & 35 & 26.7 & \\
\hline$>3$ & 100 & 39.0 & 34 & 34.0 & \\
\hline Place of transfusion & & & & & $0.8776^{\mathrm{a}}$ \\
\hline CWTH & 158 & 68.4 & 48 & 30.3 & \\
\hline Other & 73 & 31.6 & 21 & 28.7 & \\
\hline Vaccination at home (no. of doses) ${ }^{b}$ & & & & & 0.12 \\
\hline 3 & 202 & 78.9 & 54 & 26.7 & \\
\hline $1-2$ & 40 & 15.6 & 9 & 22.5 & \\
\hline 0 & 14 & 5.4 & 7 & 50.0 & \\
\hline Vaccination at hospital (no. of doses) & & & & & 0.0001 \\
\hline 4 & 15 & 5.9 & 2 & 13.3 & \\
\hline 3 & 137 & 53.5 & 26 & 18.9 & \\
\hline 2 & 44 & 17.2 & 17 & 38.6 & \\
\hline 1 & 34 & 13.3 & 8 & 23.5 & \\
\hline 0 & 25 & 9.8 & 17 & 68.0 & \\
\hline
\end{tabular}

${ }^{a}$ Fisher's exact test, otherwise -squared test.

${ }^{b}$ Possible reasons for not receiving the full complement of vaccinations include: young age, lack of vaccine in the primary health clinic, ignorance, inability to go to the primary health clinic for security reasons. Also, each primary health clinic serves a certain residential area and if a child/family is displaced they cannot get the vaccine. $H B s A g=$ hepatitis $B$ surface antigen. 
lower than the estimated carrier rate in our country, perhaps reflecting the success of the active Expanded Programme for Immunization in the country and the young age of the sample. The prevalence of $\mathrm{HBsAg}$ among children after treatment for cancer in this study was, however, higher than that found in other studies in the region. Mostafa et al. [5] in Egypt showed that the incidence of HBsAg increased from 3.6\% at the time of diagnosis to $18.2 \%$ after 6 months of therapy in 111 paediatric malignancies. Kebudi et al. [6] in Turkey studied the prevalence of $\mathrm{HBV}$ and $\mathrm{HCV}$ infections in 50 children with solid tumours at diagnosis who underwent intensive chemotherapy and multiple transfusions. At diagnosis, $4 \%$ were HBV-positive and 2\% HCV-positive; these values rose significantly to $20 \%$ and $14 \%$, respectively after therapy.

The incidence of HCV infection in our study was lower than that in other studies of children with and without malignancies in developing countries $[7,8]$. This finding might raise questions about the accuracy of HCV screening in our study, which depends on the method and on the quality of the available kits. The lack of polymerase chain reaction (PCR) testing kits in Iraq precluded confirmation of the presence of HCV in our patients.

We found no effect of age on the incidence of HBV infection, in accordance with the study of Baytan, Gunes and Gunay in Turkey [9].

Although there is no guarantee that the practices of the paramedical staff in our unit led to infection through the reuse of single medication vials or through contamination of injectable medications or flush solutions, the lack of an association with length of follow-up suggests that longterm exposure to medical and nursing procedures does not increase the risk if basic infection control measures are respected.

Our finding that children treated for leukaemia had a significantly higher incidence of $\mathrm{HBV}$ infection might be related to the duration of chemotherapy, the degree of immunosuppression and the requirement for blood products. The effect of a greater number of blood transfusions on the incidence of HBV infection might point to inadequate screening in the national blood bank centre. Several factors can lead to human immunodeficiency virus (HIV), HCV or HBV infections through blood donation: donation of blood during the infectious "window period" following infection when the available tests cannot detect infection; false-negative results due to poor test sensitivity (less than $100 \%$ ), and blood donations falsely labelled as virus-negative due to errors in sampling, testing or recording of test results. In addition, blood donations collected from individuals with fluctuating or waning levels of HBsAg during the later stages of $\mathrm{HBV}$ carriage can give false-negative results during donation [3].

Our study shows that prior vaccination does not prevent infection, perhaps raising the question of the efficacy of the vaccines given, the reliability of histories taken from the parents and the degree of attenuation of the immune system during chemotherapy.
A shortage of kits for measuring antibodies to HBsAg precluded us from assessing the response to vaccination. Our results show, however, a statistically significant association between the number of doses of vaccine given in hospital and a reduction in the incidence of hepatitis, which implies that the strict immunization policy we use in our oncology unit was successful. This finding differs from findings in 2 studies on children with acute lymphoblastic leukaemia treated at the Tata Memorial Hospital in India. In the first study, only $10.5 \%$ of 162 patients developed protective levels of anti-HBsAg after 3 double doses of HBV vaccine, and $48.0 \%$ became infected with $\mathrm{HBV}$ [10]. In the second study, children were given 5 primary doses at monthly intervals, followed by a booster 1 year after the first dose. Serum antibodies were detected in only $30 \%$ of children who received all 6 doses of vaccine, and $43 \%$ became infected with HBV [11]. Fioredda et al. in Italy, however, found that the addition of boosters to the regular vaccination schedule was effective if they were given at least 6 months after the end of treatment [12]. Further study is needed to confirm these observations.

\section{Conclusions}

The high rate of acquisition of HBV infection in children with malignancy found in this study indicates the need for better screening of blood products and rigorous adherence to aseptic techniques in the management of this group of patients.

\section{References}

1. Kebudi R, Agaoglu L, Badur S. The seroprevalance of HIV-1 and HBV infections in multitransfused pediatric hematologyoncology patients in Istanbul. Journal of Pediatric Hematology/ Oncology, 1992, 9:389-391.

2. Dumpis $U$ et al. An outbreak of HBV and HCV infection in a paediatric oncology ward: epidemiological investigations and prevention of further spread. Journal of Medical Virology, 2003, 69(3):331-338.
3. Hepatitis B. Geneva, World Health Organization, 2008 (Factsheet No. 204) (http://www.who.int/mediacentre/ factsheets/fs204/en/, accessed 28 December 2012).

4. Immunization service delivery. Hepatitis B. Countries using hepatitis $B$ vaccine. Geneva, World Health Organization, 2009 (http://www.who.int/immunization_delivery/new_ vaccines/hepb/en/index4.html, accessed 28 December 2012). 
5. Mostafa A et al. Seroprevalence of hepatitis B and C in pediatric malignancies. Journal of the Egyptian National Cancer Institute, 2003, 15:33-42.

6. Kebudi R et al. Seroprevalence of hepatitis B, hepatitis C and human Immunodeficiency virus infection with cancer at diagnosis and following therapy in Turkey. Medical and Pediatric Oncology, 2000, 34:102-105.

7. Mollah $\mathrm{AH}$ et al. Common transfusion-transmitted infectious agents among thalassaemic children in Bangladesh. Journal of Health, Population and Nutrition, 2003, 21:67-71.

8. De Paula EV et al. Transfusion-transmitted infections among multi-transfused patients in Brazil. Journal of Clinical Virology, 2005, 34(Suppl. 2):S27-S32.
9. Baytan B, Gunes AM, Gunay U. Efficacy of primary hepatitis B immunization in children with acute lymphoblastic leukemia. Indian Pediatrics, 2008, 45:265-270.

10. Goyal $S$ et al. Hepatitis B vaccination in acute lymphoblastic leukemia. Leukaemia Research, 1998, 22:193-195

11. Somjee $S$ et al. Hepatitis B vaccination in children with acute lymphoblastic leukemia: results of an intensified immunization schedule. Leukaemia Research, 1999, 23:365-367.

12. Fioredda $\mathrm{F}$ et al. Re-immunisation schedule in leukaemic children after intensive chemotherapy: a possible strategy. European Journal of Haematology, 2005, 74:3-20.

\section{Hepatitis B and C in the Eastern Mediterranean Region}

Despite the availability of effective prevention strategies, hepatitis B virus (HBV) and hepatitis C virus (HCV) transmission occur throughout the WHO Eastern Mediterranean Region. In fact it is estimated that around 4.3 million persons are infected with HBV and 800000 persons with HCV in the Region each year. The cost to treat patients with chronic HBV or HCV infection far outweighs the cost of implementing prevention programmes. Strategies recommended by the World Health Organization to reduce HBV and HBC infection include: sustainable hepatitis $B$ vaccination of all infants, including provision of a first dose of vaccine within 24 hours of birth; vaccination and education of all persons occupationally exposed to blood and also health care students, and education and quality assurance in health care to ensure patient safety, injection safety and safe dental care.

Source: The growing threats of hepatitis B and C in the Eastern Mediterranean Region: a call for action (http:// applications.emro.who.int/docs/EM_RC56_3_en.pdf) 